\title{
Comparison between cystourethrography and sonourethrography in preoperative diagnostic management of patients with anterior urethral strictures
}

\author{
Jakub Krukowski, Adam Kałużny, Jakub Kłącz, Marcin Matuszewski
}

Department of Urology, Medical University of Gdańsk, Gdańsk, Poland

\begin{abstract}
Aim: To evaluate the urethral lesions and the degree of spongiofibrosis using cystourethrography (CUG) and sonourethrography (SUG) in order to propose the best imaging method for further surgical treatment. Material and methods: The study involved 66 patients with anterior urethral strictures with indication for urethroplasty. Results of CUG and SUG were compared with each other and data from surgical protocol. Results: Totally 72 strictures were detected; 47 in the bulbar part of urethra and 25 in the penile urethra. The mean length of the stenosis was $16.43 \mathrm{~mm}$ for CUG and $27.41 \mathrm{~mm}$ for SUG and $31.05 \mathrm{~mm}$ during surgery. The correlation levels between imaging techniques and intraoperative measurements were 0.55 $(\mathrm{p}<0.001)$ for CUG and $0.73(\mathrm{p}<0.001)$ for SUG. After dividing the strictures according to their location, better correlation for stenoses was obtained in penile urethra: $0.66(p<0.001)$ for CUG and $0.86(p<0.001)$ for SUG. Conclusions: SUG seems to be a simple and fast examination to evaluate urethral strictures. It is more accurate in comparison to CUG and gives a possibility to assess the spongiofibrosis. This information suggests that SUG can be a good complement to CUG in diagnosis of anterior urethtral strictures.
\end{abstract}

Keywords: anterior urethral stricture; ultrasonography; sonourethrography; urethrography; spongiofibrosis

\section{Introduction}

Urethral stricture is a fairly common problem in urological practice, affecting 229-627 per 100000 men, with an increase in frequency at the age of 60-65 [1,2]. Basic treatment modalities include visual internal urethrotomy (VIU) and urethroplasty. The selection of the surgical treatment method should be based on the estimation of the length and location of the stricture, performed before the surgery.

The main imaging methods used for this purpose are retrograde cystourethrography (RCUG) and voiding cystourethrography (VCUG). They were used for over one

Received 10.06.2018 Accepted 19.09.2018

Med Ultrason

2018, Vol. 20, No 4, 436-440

Corresponding author: Jakub Krukowski, MD, Department of Urology,

Medical University of Gdańsk,

Smoluchowskiego 17 St., Gdańsk, Poland

E-mail: jakub.i.krukowski@gmail.com hundred years and are still regarded a "golden standard" for the diagnosis of urethral stricture in men $[3,4]$.

The main shortcoming of the abovementioned methods is that they provide no information about the disease process within the tissues surrounding the urethra. Lack of the information about the spongiofibrosis make many urologists continue VIU even if the chances of the treatment success are much lower.

In 1988 McAninch was the first to describe the use of ultrasonography in the diagnostics of anterior urethral strictures. His results demonstrated that the length of the stricture could be more precisely assessed with ultrasonography than with cystourethrography [5]. From that moment the importance of ultrasonography in reconstructive urology increased significantly. Sonourethrography (SUG), allows not only to localise and to measure the urethral stricture length, but also to assess the spongiofibrosis, which is important for the choice of treatment modality [6].

The aim of our study was to evaluate the accuracy of classical x-ray urethrographic methods and SUG in the 
diagnosis of the urethral stricture's length. Additionally, to verify the influence of spongiofibrosis on the accuracy of SUG. The primary aim of this study was to compare the estimated stricture length measured in CUG and SUG with intraoperative measurement of the stricture. The second aim was to calculate the correlation between the imaging results and the intraoperative measurement: overall and according to the localisation of the stricture, the etiology of urethral damage and degree of occlusion of spongiofibrosis.

\section{Material and methods}

This study was approval by the local Ethics Committee. Written, informed-consent was obtained from all patients included in the study.

The study was performed between June 2016 and March 2018 and included patients with clinical features suggesting urethral stricture, qualified to open urethroplasty. The exclusion criteria were meatal or submeatal stenosis, active urinary tract infection, bladder outlet obstruction or urinary retention caused by conditions other than urethral stricture.

Sixty-six male patients were included. The initial diagnosis of urethral stricture was made based on the patient's history and the result of previous urethrographies and uroflowmetries. New RCUG and VCUG studies, SUG and uroflowmetry were performed in each patient (fig 1). All tests were performed and interpreted by the same urology specialist. The presence of urethral strictures, the number, location and length were analysed for each imaging method, together with the level of spongiofibrosis (in ultrasonographic imaging only). The potential presence of other pathologies, such as stones, fistulas and false passages, was also evaluated.

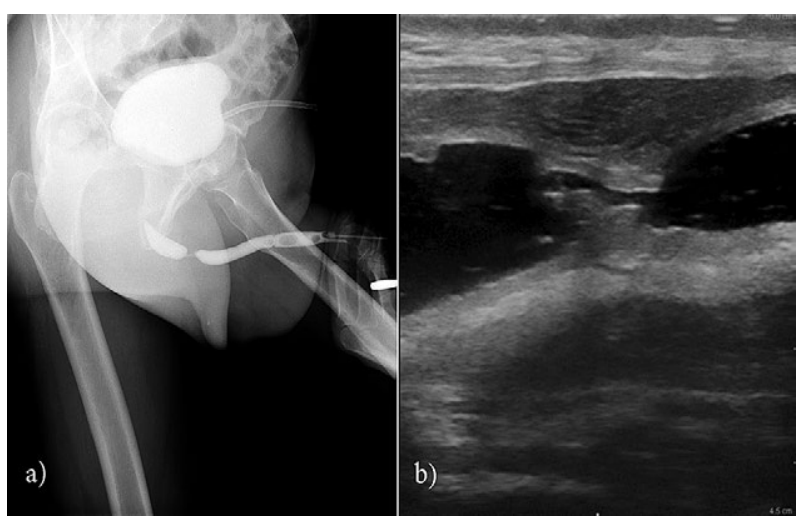

Fig 1. Stricture in the bulbar part of urethra examined by a) cystourethrography $-11 \mathrm{~mm}$ length and b) sonourethrography $-21 \mathrm{~mm}$ length. The intraoperative length was $20 \mathrm{~mm}$.
Ultrasonography evaluation was performed with a BK Medical Flex Focus 800 equipped with a $18 \mathrm{~L} 5 \mathrm{MHz}$ linear transducer operated at a transmission frequency from 6 to $15 \mathrm{MHz}$. After disinfection of the urinary meatus (external urethral orifice) and installation of $12 \mathrm{Ch}$ Foley's catheter in the navicular fossa of urethra the $0.9 \%$ physiological solution of saline was injected into the urethra. The normal urethra presented in ultrasonography as an uniform, echo-free area, 8-10 $\mathrm{mm}$ in diameter. Parts of the urethra that did not comply with the stretching during saline infusion were described as strictures. Areas of spongiofibrosis were identified as hyperechogenic areas, compared to the normal echogenicity of corpus spongiosum, sometimes with calcifications. The rate of urethral impairment was evaluated and classified based on the level of the stricture [5] and the results from the imaging studies were compared with the intraoperative measurements (Table I). The length of the urethral stricture and the extent of spongiofibrosis were verified during the surgery.

Table I. Parameters for assessing severity of spongiofibrosis

\begin{tabular}{llll}
\hline Degree of & SUG & \multicolumn{2}{c}{ Operative findings } \\
\cline { 2 - 4 } spongiofibrosis & $\begin{array}{l}\text { Degree of } \\
\text { occlusion }\end{array}$ & $\begin{array}{l}\text { Colour of the } \\
\text { urethral mucosa }\end{array}$ & $\begin{array}{l}\text { Difficulty } \\
\text { in incision }\end{array}$ \\
\hline I (Mild) & $<33 \%$ & Pink & Mild \\
II (Moderate) & $33-50 \%$ & Grey & Moderate \\
III (Severe) & $>50 \%$ & White & Severe \\
\hline
\end{tabular}

SUG - sonourethrography

\section{Statistical analysis}

Continuous variables were reported as a mean and range. Spearman correlation analysis was used to determinate the correlation between intraoperative measurement of stricture and imaging studies (CUG or SUG). A p-value $<0.05$ was considered statistically significant. Statistics were analyzed using STATISTICA (Statistica 12.0, StatSoft Inc., USA)

\section{Results}

The mean age of the patients was 53.9 years (range between 19-79, median 59). The mean maximal urethral flow (Qmax) was $3.5 \mathrm{~mL} / \mathrm{s}(0-17.6)$. Etiology of the urethral strictures and their location is presented in Table II.

Surgery confirmed the presence of 72 strictures: 47 cases within the bulbar part of urethra and 25 in the penile urethra. Six patients presented with two independent strictures, both requiring surgical treatment.

Out of the total number of 72 strictures, 70 were diagnosed in CUG. Two cases, seen in the ultrasonography, and further confirmed during the surgery, were not detected with CUG methods. In addition, two other patients 
Table II. Etiology and location of the urethral strictures

\begin{tabular}{llll}
\hline Etiology & N & \multicolumn{2}{c}{ Stricture localisation } \\
\cline { 3 - 4 } & & Bulbar & Penile \\
\hline Pelvic trauma & 18 & 17 & 1 \\
Post endourethral procedures & 17 & 6 & 11 \\
Post catheterisation & 18 & 12 & 6 \\
Idiopathic & 17 & 12 & 5 \\
Hypospadiasis & 2 & 0 & 2 \\
\hline
\end{tabular}

$\mathrm{N}$ - number of urethral strictures

Table III. Mean (range) stricture length (in millimetres)

\begin{tabular}{llll}
\hline & Overall & Bulbar & Penile \\
\hline CUG & $16.43(0-75)$ & $13.5(2-40)$ & $21.9(0-75)$ \\
SUG & $27.41(3-75)$ & $24.9(11-65)$ & $32.1(3-75)$ \\
Surgery & $31.05(2-120)$ & $26.9(15-70)$ & $38.8(2-120)$ \\
\hline
\end{tabular}

CUG - cystourethrography; SUG - sonourethrography

Table IV. Coefficients correlation (r) of the urethral stricture length measured during imaging techniques and surgery

\begin{tabular}{llll}
\hline & Overall $(\mathbf{n}=72)$ & Bulbar $(\mathbf{n}=\mathbf{4 7})$ & Penile $(\mathbf{n}=\mathbf{2 5})$ \\
\hline CUG & $0.55(\mathrm{p}<0.001)$ & $0.39(\mathrm{p}=0.007)$ & $0.66(\mathrm{p}<0.001)$ \\
SUG & $0.73(\mathrm{p}<0.001)$ & $0.58(\mathrm{p}<0.001)$ & $0.86(\mathrm{p}<0.001)$ \\
\hline
\end{tabular}

CUG - cystourethrography; $\mathrm{n}$ - number of strictures; SUG sonourethrography

were diagnosed with false passages, which were subsequently confirmed during the surgery.

When the results of the imaging studies were compared with the intraoperative measurements - ultrasonographic imaging was found to be the most accurate in the estimation of the stricture length $(27.41 \mathrm{~mm}$ vs. 16.43 $\mathrm{mm}$; intraoperative measurement: $31.05 \mathrm{~mm}$ ). The small- est difference between the ultrasonographic and intraoperative measurements was seen for the bulbar strictures (Table III).

In all cases SUG evaluation of the stricture length showed better correlation with the measurement performed during the surgery $(\mathrm{R}=0.73 ; \mathrm{p}<0.001)$, compared with CUG $(\mathrm{R}=0.55 ; \mathrm{p}<0.001)$.

When the strictures were analysed according to their location, the highest statistically significant correlation between the length evaluation from the imaging studies (both CUG and SUG) and the intraoperative measurements was found for the strictures within the penile urethra (Table IV).

In all the etiological groups better correlation with surgery was found for the SUG measurements, compared with CUG. Both for SUG and CUG the best correlation was demonstrated for post traumatic catheterisation and idiopathic strictures (Table V).

The degree of spongofibrosis, based on McAninch's scale, negatively affected the accuracy of the SUG stricture length evaluation, compared with the measurement during urethroplasty (Table VI).

Table VI. Comparison of the ultrasonographic estimation of the stricture length with the intraoperative measurements in patients with different degrees of spongiofibrosis (based on [5] classification)

\begin{tabular}{lllll}
\hline $\begin{array}{l}\text { Degree of } \\
\text { spongiofibrosis }\end{array}$ & SUG & \multicolumn{3}{l}{ Surgery } \\
\cline { 2 - 5 } & $\begin{array}{l}\text { Mean length } \\
\text { (range), mm }\end{array}$ & $\mathbf{r}$ & $\begin{array}{l}\text { Mean length } \\
\text { (range), mm }\end{array}$ & $\mathbf{r}$ \\
\hline I $(\mathrm{n}=5)$ & $12.4(3-35)$ & 1.0 & $13.6(3-40)$ & 1.0 \\
II $(\mathrm{n}=19)$ & $33.4(6-75)$ & 0.716 & $42.7(2-120)$ & 1.0 \\
III $(\mathrm{n}=48)$ & $26.6(11-65)$ & 0.631 & $26.6(15-70)$ & 1.0 \\
\hline
\end{tabular}

$\mathrm{n}$ - number; $\mathrm{r}$ - coefficients correlation; SUG - sonourethrography

Table V. Comparison between the results of the imaging techniques and the intraoperative measurement of the urethral stricture according to the etiology

\begin{tabular}{|c|c|c|c|c|c|c|}
\hline \multirow[t]{2}{*}{ Etiology } & \multicolumn{2}{|c|}{ CUG } & \multicolumn{2}{|c|}{ SUG } & \multicolumn{2}{|l|}{ Surgery } \\
\hline & $\begin{array}{l}\text { Mean (range), } \\
\text { mm }\end{array}$ & $\mathbf{r}$ & $\begin{array}{l}\text { Mean (range), } \\
\text { mm }\end{array}$ & $\mathbf{r}$ & $\begin{array}{l}\text { Mean (range), } \\
\text { mm }\end{array}$ & $\mathbf{r}$ \\
\hline Post endourethral procedures & $\begin{array}{l}14.5 \\
(2-47)\end{array}$ & $0.43(p=0.08)$ & $\begin{array}{l}27.1 \\
(5-54)\end{array}$ & $0.71(\mathrm{p}=0.001)$ & $\begin{array}{l}33.5 \\
(5-70)\end{array}$ & 1.0 \\
\hline Post catheterisation & $\begin{array}{l}21.3 \\
(5-75)\end{array}$ & $0.62(\mathrm{p}=0.006)$ & $\begin{array}{l}32.4 \\
(15-75)\end{array}$ & $0.77(\mathrm{p}<0.001)$ & $\begin{array}{l}34.2 \\
(15-100)\end{array}$ & 1.0 \\
\hline Postraumatic & $\begin{array}{l}11.3 \\
(0-30)\end{array}$ & $0.39(\mathrm{p}=0.11)$ & $\begin{array}{l}21.4 \\
(5-35)\end{array}$ & $0.62(\mathrm{p}=0.006)$ & $\begin{array}{l}20.6 \\
(5-30)\end{array}$ & 1.0 \\
\hline Idopathic & $\begin{array}{l}15.9 \\
(0-60)\end{array}$ & $0.6(p=0.01)$ & $\begin{array}{l}26.5 \\
(3-65)\end{array}$ & $0.77(\mathrm{p}<0.001)$ & $\begin{array}{l}34.5 \\
(2-120)\end{array}$ & 1.0 \\
\hline Hypospadiasis & $\begin{array}{l}39 \\
(18-60)\end{array}$ & NA & $\begin{array}{l}46.5 \\
(33-60)\end{array}$ & NA & $\begin{array}{l}47.2 \\
(35-60)\end{array}$ & 1.0 \\
\hline
\end{tabular}

CUG - cystourethrography; NA - non-available; $r$ - Spearman's coefficients correlation; SUG - sonourethrography 


\section{Discussions}

Our results confirm the value of SUG in urethral strictures' diagnosis. We have confirmed a better accuracy of SUG, compared with CUG, in estimation of the stricture length for both penile and bulbar urethra reported earlier by other authors [7-9]. After dividing strictures according to their location, our results were similar to those of Mitterberger et al [9]. We also noted a closer correlation of SUG estimates with surgery measurements for bulbar and penile urethra.

According to the literature our study seems to be the first one that describes the influence of the etiology of the stricture on the accuracy of the imaging studies. We have demonstrated the highest accuracy of both CUG and SUG for strictures arising after traumatic catheterisations and for idiopathic stenoses. On the other hand, the worst results were observed for the strictures caused by a traumatic origin. In our opinion, this could be possibly explained by the fact that postraumatic strictures are usually located in the bulbar urethra and are characterised by very narrow or completely closed lumen and high levels of spongofibrosis, which makes the accurate tracing of course of the urethra difficult.

For over 100 years CUG has been the standard imaging technique for the diagnosis of urethral strictures [3]. Acquisition of meaningful x-ray images, although seemingly easy, in fact requires experience and accuracy. Currently the procedure follows the protocol by McCallum [10]. In order to visualise the whole length of the urethra, the test should include two parts: RCUG and VCUG. The first part allows good imaging of the anterior part of the urethra (penile and bulbar) while the second is better for visualising pathologies of the posterior urethra (membranous and prostatic parts of the urethra). The well-known limitations of this imaging technique result from the oblique position of the patient during the exam and excessive stretching of the penis. The highest discrepancy is usually seen for the membranous urethra. In addition, RCUG, like any other radiological examination, exposes the patient to x-ray irradiation. Mean radiation dose during CUG is up to $11.4 \mathrm{mGy}$ [11]. RCUG sensitivity is estimated at $75-100 \%$ and specificity at $72-97 \%$ [12-14].

However, the main drawback of RCUG is that it does not show the scar tissue around the strictured urethra. Imprecise assessment of the spongiofibrosis make the choice of the surgical method difficult, first of all leading to the excessive rate of VIUs and causing also the exact planning of the urethroplasties challenging.

In 1988 McAninch was the first to describe the use of ultrasonography in the diagnostics of urethral strictures [5]. First, a $5 \mathrm{MHz}$ linear transducer was used, which was applied to the dorsal surface of the penis. The constant development of the ultrasound equipment allowed for more and more accurate examination. Currently, high frequency linear transducers are used in SUG allowing for a thorough examination of the entire anterior urethra. A significant advantage of the ultrasound examination, in addition to the lack of invasiveness, is that it gives multiplanar imaging, compared to CUG, which provides only a two-dimensional image.

Sensitivity of SUG ranges from 66 to $100 \%$ with a specificity of 97-98\% [5-7]. Ultrasound can also be used during surgery to assess the location, depth and extent of the incision of urethrotomy, which is another asset of this method. An accurate assessment of the incision performed in the fibrotic urethra reduces the risk of stricture relapse $[15,16]$.

SUG does not share limitations of RCUG. The fibrotic area is clearly visible in ultrasonography as a hyperechogenic structure, sometimes with areas of calcification. McAninch et al suggested a three level spongiosis classification, based on the extent of the urethral stricture [5]. In 1996 Chiou et al introduced a five stages scale, where the number and the length of strictures were the main components, together with spongiofibrosis [17]. The overall sensitivity of SUG in spongiofibrosis evaluation is $51.7-56 \%[8,18]$, but when McAninch's classification of stenoses is applied, it increases to $83 \%$ for grade III.

An accurate evaluation of the stricture length in the imaging studies is necessary for the proper choice of the treatment method. In the past, when RCUG was the main imaging methods, "end-to-end" urethroplasty was recommended only for strictures shorter than $1 \mathrm{~cm}$ [19]. Currently, when SUG is employed, the recommendations have been extended to $2.5 \mathrm{~cm} \mathrm{[15].}$

Development of new techniques in ultrasonography gave a new ability in diagnostic of urethral strictures. Sonoelastography (SE) aims to evaluate the tissue elasticity level. This technique allows better accuracy in the evaluation of the stricture length, compared to RCUG. It also provides a higher accuracy in the measurements of stricture length and evaluation of spongiofibrosis, compared with standard SUG $[20,21]$. The novelty in SUG is the three-dimensional visualisation of urethral strictures [22].

The most advanced examination used in the diagnosis of urethral strictures is MRI. Similarly to ultrasound, MRI provides information about the tissues surrounding the urethra and the degree of spongiofibrosis. The sensitivity of both imaging examinations in the diagnosis of strictures of anterior urethra is at a similar level and reaches $100 \%$. Similar results are obtained in the assessment of spongiofibrosis [23]. 
In our opinion, preoperative diagnosis of urethral strictures should be obtained in two imaging examinations. CUG confirm the urethral strictures and show their localisation, and SUG described urethral damage: length of stricture and degree of spongiofibrosis. A combination of these two examinations help to plan the appropriate surgical treatment.

The biggest limitation of this study that could affect the final result is that CUG and SUG were performed by only one experienced examiner. Therefore, no data were obtained regarding inter-observer and intra-observer variability.

\section{Conclusions}

SUG is a useful imaging method for the diagnostics of urethral strictures. Higher accuracy in estimation of the stricture length together with the possibility to assess the extent of spongiofibrosis are its main advantages over CUG. Information from SUG permits an appropriate planning of treatment for patients with urethral strictures.

\section{Conflict of interest: none}

\section{References}

1. Santucci RA, Joyce GF, Wise M. Male urethral stricture disease. J Urol 2007;177:1667-1674.

2. Alwaal A, Blaschko S, McAninch JW, Breyer BN. Epidemiology of urethral stricture. Transl Androl Urol 2014;3:209213.

3. Cunnigham JH. The diagnosis of stricture of the urethra by Roentgen rays. Trans Am Assoc Genitourin Surg 1910;5:369-371.

4. McCallum RW, Colapinto V. The role of urethrography in urethral disease. Part I. Accurate radiological localisation of the membranous urethra and distal sphincter in normal male subjects. J Urol 1979;122:607-611.

5. McAninch JW, Laing FC, Jeffrey RB Jr. Sonourethrography in evaluation of urethral strictures: a preliminary report. J Urol 1988;139:294-297.

6. Morey AF, McAninch JW. Sonographic staging of anterior urethral strictures. J Urol 2000;163:1070-1075.

7. Morey AF, McAninch JW. Role of preoperative sonourethrography in bulbar urethral reconstruction. J Urol 1997;158:1376-1379.

8. Gupta N, Dubey D, Mandhani A, Srivastava A, Kapoor R, Kumar A. Urethral stricture assessment: a prospective study evaluating urethral ultrasonography and conventional radiological studies. BJU Int 2006;98:149-153.
9. Mitterberger M, Christian G, Pinggera GM, et al. Gray scale and color Doppler sonography with extended field of view technique for the diagnostic evaluation of anterior urethral strictures. J Urol 2007;177:992-996.

10. McCallum RW. The adult Male urethra: normal anatomy, pathology, and method of urethrography. Radiol Clin North Am 1979;17:227-244.

11. Livingstone RS, Koshy CG, Raj DV. Evaluation of work practices and radiation dose during adult micturating cystourethrography examinations performed using a digital imaging system. Br J Radiol 2004;77:927-930.

12. Choudhary S, Singh P, Sundar E, Kumar S, Sahai A. A comparison of sonourethrography and retrograde urethrography in evaluation of anterior urethral strictures. Clin Radiol 2004;59:736-742.

13. Andersen J, Aagaard J, Jaszczak P. Retrogarde urethrography in postoperative control of urethral strictures treated with Visual internal urethrotomy. Urol Int 1987;42:390-391.

14. Mahmud SM, El KS, Rana AM, Zaidi Z. Is ascending urethrogram mandatory for all urethral strictures? J Pak Med Assoc 2008;58:429-431.

15. Gluck CD, Bundy AL, Fine C, Loughlin KR, Richie JP. Sonographic urethrogram; comparison to roentgenic techniques in 22 patients. J Urol 1988;140:1404-1408.

16. Klosterman PW, Laing FC, McAninch JW. Sonourethrography in the evaluation of urethral stricture disease. Urol Clin N Am 1989;16:791-797.

17. Chiu RK, Anderson JC, Tran T, Patterson RH, Wobig R, Taylor RJ. Evaluation of urethral strictures and associated abnormalities using high-resolution and color Doppler ultrasound. Urology 1996;47:102-107.

18. Ani C, Akpayak I, Dakum N, Ramyil V, Shuaibu S. Sonourethrography in the evaluation of anterior urethral stricture. J West Afr Coll Surg 2012;2:1-13.

19. Webster GD, Koefoot RB, Sihelnik SA. Urethroplasty management In 100 cases of urethral stricture: rationale for procedure selection. J Urol 1985;134:892-898.

20. Talreja SM, Yadav SS, Tomar V, Agarwal N, Jaipal U, Priyadarshi S. 'Real-time sonoelastography' in anterior urethral strictures: a novel technique for assessment of spongiofibrosis. Cent European J Urol 2016;69:417-424.

21. Talreja SM, Tomar V, Yadav SS, et al. Comparison of sonoelastography with sonourethrography and retrograde urethrography in evaluation of male anterior urethral strictures. Turk J Urol 2016;42:84-91.

22. Chen L, Feng C, Lv XG, et al. Three-Dimensional Computerized Model Based on the Sonourethrogram: A Novel Technique to Evaluate Anterior Urethral Stricture. J Urol 2018;199:568-575.

23. El-Ghar MA, Osman Y, Elbaz E, Refiae H, El-Diasty T. MR urethrogram versus combined retrograde urethrogram and sonourethrography in diagnosis of urethral stricture. Eur J Radiol 2010;74:e193-e198. 